\title{
Emotions in young tennis players: A new tennis-specific scale
}

\section{Antonio Daino, Vanessa Costa, Riccardo Martoni \& Sergio Costa}

Italian Tennis Federation, Italy.

\begin{abstract}
This article describes the development of the "Scale Perception Emotion Tennis" (SPET). This scale tries to contribute to the understanding and assessment of responses related to the inadequate management of emotions in tennis competition. It delineates how the SPET tool could represent a first step in the direction of increasing the awareness of the players and could be used by the coaches to compare their perception of the player's emotions with the one of their athletes.
\end{abstract}

Key words: scale, emotions, tennis questionnaire, test SPET.

Received: 3 October 2021

Accepted: 24 November 2021

Corresponding author: Antonio Daino.Email: adaino@libero.it

\section{INTRODUCTION}

Emotions are multifaceted subjective feelings reflecting expected, current, or past interactions with the environment and play a fundamental role in human adaptation and performance by improving sensory intake, detection of relevant stimuli, readiness to behavioral responses, decisionmaking and interpersonal social interactions (Robazza \& Ruiz, 2018). These beneficial effects enhance human health and performance in any endeavor. For many years, sport psychologists have been concerned with the study of the deleterious effects of stress and anxiety purported to the main factors in the failure of performers to fully and effectively use their skills (Robazza, 2006).

These aspects are present in tennis, too, where the selfefficacy degree to cope with the match tasks influences the emotions and their perception (Costa et al., 2015). For this reason, the matches arouse both in the audience and in the players an enormous emotional involvement; the young tennis players are often forced to deal with strong emotions that tend to affect their performance negatively. Anxiety, sadness, fear and anger are emotions felt very often, and young players in comparison with professional players are less able to understand and explain these oppressive feelings, and cope with them effectively during the tournament.

The interest in the emotion field first appeared within the Italian Tennis Federation many years ago, but took shape in a research project which started in 2016 when the mental staff of the R. Lombardi Institute, under the direction of Michelangelo Dell'Edera and coordinated by Antonio Daino, put forward the "ABC of Emotion Project". This project was designed to investigate the emotions connected to the competitive context in regarding players of national level Under-12 (Daino \& Uberti, 2014). This work, conducted on 30 selected (best) Italian tennis players (balanced by gender. age, and level of play), revealed that, asking the young tennis players to list the emotions they usually experience oncourt, $70 \%$ of them started with negative emotions as a first response (anxiety, anger and fear), while only $30 \%$ reported positive emotions (joy, happiness and serenity). This may be attributable to the fact that, in youth sports, excessive emphasis is placed on result instead of fun, which conversely should be a fundamental element in these phases of sport (Merkerl, 2013).
For these reasons, a tool was developed to detect and measure these feelings with the goal of using this knowledge to teach how to manage the emotions. It is called the "Scale Perception Emotion Tennis" (SPET) and could be established thanks to a self report questionnaire. The goal of this questionaire was to determine the more dominant emotional aspects while performing competitive tennis.

The purpose of the following research was to monitor ideas, thoughts, beliefs, and emotional experiences in relation to tennis performance in the different age groups, levels and genders using the new proposed scale. This information would therefore be useful not only in improving the players' emotional awareness, but also in promoting the selfregulation of the emotions perceived during the matches.

\section{METHOD}

\section{Participants}

The questionnaire was proposed to 136 participants, 93 male and 43 female, with an average age of 20.27 years old, with SD 8.6, and grouped in 4 different groups based on each specific tennis role (coaches, Under-16 Italian national team players, Under-16 competitive tennis players and Under-16 amateurs).

\section{Table 1}

Mean and SD of the 4 groups.

\begin{tabular}{lccc}
\cline { 2 - 4 } & Num. & Mean & SD \\
\hline Coaches & 55 & 28.90 & 7.09 \\
Italian National Team Players & 29 & 15.89 & 1.84 \\
Competitive Tennis Players & 25 & 12.84 & 1.74 \\
Amateurs & 27 & 14.25 & 2.24 \\
\hline
\end{tabular}




\section{Questionaire}

The "Scale Perception Emotion Tennis" (SPET) was administered in the post-game interviews of the players between 2012-2014 with the Italian Tennis Federation mental trainers, and produced a first version of 30 items in total. This version was revised to have a final version with 20 items, using only those aimed at investigating the specificity of tennis emotions. The questionnaire evaluated 3 different areas: Emotions, Thoughts and Behavior and it made up of of the following items.

1. Competing makes me feel at ease and energised.

2. My performance gets better while playing in front of a crowd.

3. I tend to perform better during practice than during competitive matches.

4. I am very afraid of losing the match.

5. I hop on my toes to keep active and activated.

6. I use a breathing technique to better adjust to the pressure of a match.

7. I cannot stand the pressure of the third set and can't wait for it to end.

8. I keep my fingers crossed not to play against certain players.

9. I am able to focus and not get distracted even during clutching moments.

10. I play my best tennis during tough matches.

11. I feel too much tension during a match.

12. My opponents play best when they are playing against me.

13. I am able to release tension between points.

14. I am able to control my anger after an unforced error.

15. I get stuck on clutching points.

16. My timing gets worse when I am under pressure.

17. I am able to relax and calm down during breaks between matches.

18. I play better during competitive matches than in practice.

19. I am overwhelmed by my thoughts.

20. I miss opportunities due to indecision.

The players were then asked to answer, thinking about what they felt during the tournament matches, indicating for each item, on the basis of a four-point Likert scale, if that feeling was perceived "always", "often", "sometimes" or "never". For the assessment, an increasing or decreasing score was then assigned, from four to one, depending on the orientation of the specific question.

\section{Procedure}

The participants, in groups, were invited to answer to the questionnaire, being as sincere as possible, since the test was absolutely anonymous with no right/wrong answers.

\section{Statistical Analysis}

Data analyses were performed using Statistica 8.0. The variables normality distribution was evaluated with the Shapiro-Wilk test and, since the variables results were not normally distributed, nonparametric tests were run for Groups Comparison and Cluster Analysis. Thresholds of significance were set at $\mathrm{p}<0.05$.

\section{RESULTS}

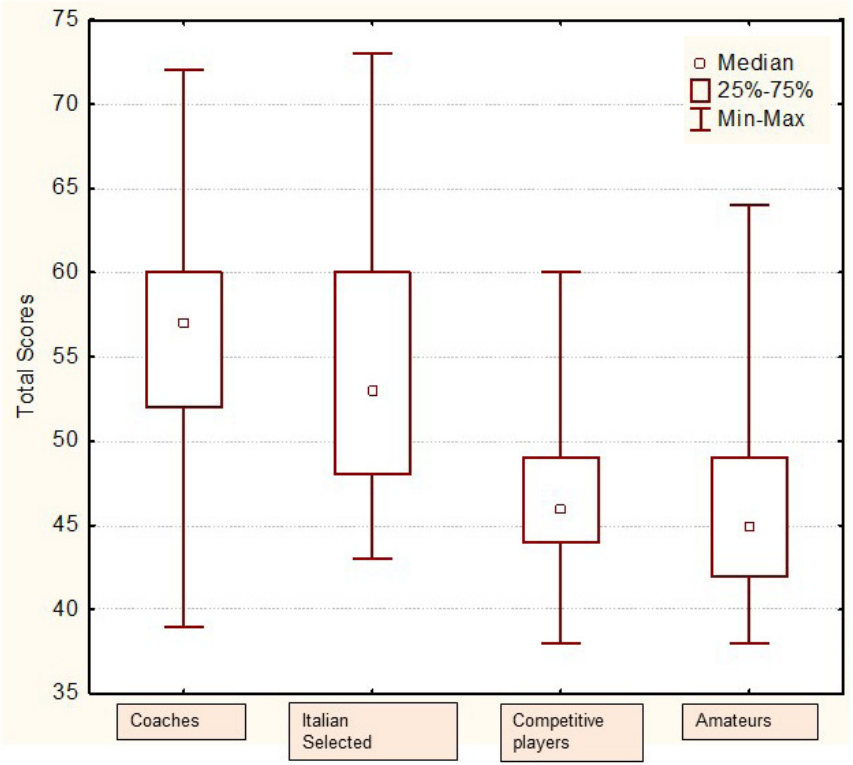

Figure 1. Total score comparison in the four groups.

Kruskal-Wallis analysis shows that groups differed of the total score at the questionnaire (Fig.1) $[\mathrm{H}(3, \mathrm{~N}=136)=47,67597 \mathrm{p}$ $=, 0000]$. Moreover, Mann-Whitney U Test comparisons show some differences between groups [Coaches vs Competitive Tennis Players (Z: 5.08; p: 0.000); Coaches vs Amateurs (Z: 5.37; p:0.000); Italians Selected vs Competitive Tennis Players (Z: 3.96; p:0.000); Italians Selected vs Amateurs (Z: 4.27; p: 0.000)], with the exception of Coaches vs. Italians Selected comparison ( $Z: 1.16 ; \mathrm{p}: 0.245)$ and Competitive Tennis Players vs Amateurs comparison (Z: 0,43; p:0.781).

According to the k-means data, the scree plot (Fig. 2) shows the two-cluster solution with 76 subjects in cluster 1 (Coaches and Italians Selected) and 60 subjects in cluster 2 (Competitive Tennis players and Amateurs).

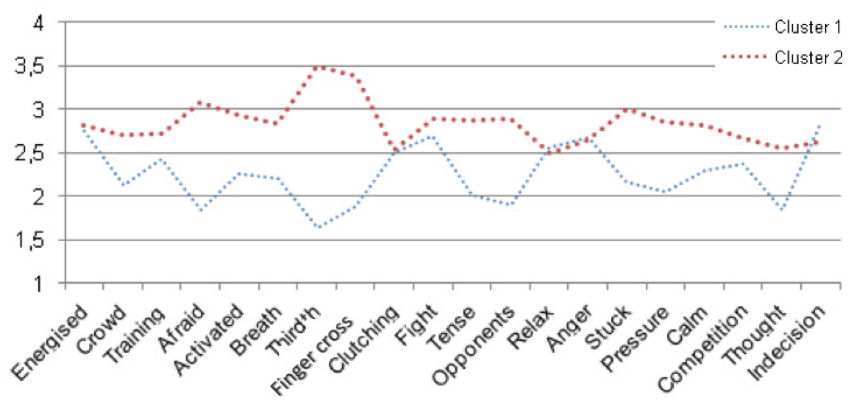

Figure 2. Plot of Means for each cluster. 
Table 2

Means and SD of the two clusters for each questionnaire's item.

\begin{tabular}{|c|c|c|c|c|c|c|c|c|}
\hline & & & \multicolumn{2}{|c|}{ Cluster 1} & \multicolumn{2}{|c|}{ Cluster 2} & \multicolumn{2}{|c|}{ Mann-Whitney U Test } \\
\hline & & & Mean & Std.Dev. & Mean & Std.Dev. & Z & p-level \\
\hline 1 & Energised & $\mathrm{E}$ & 2,75 & 0,75 & 2,82 & 0,60 & 0,55 & 0,580 \\
\hline 2 & Crowd & $\mathrm{T}$ & 2,12 & 0,88 & 2,71 & 0,88 & 3,57 & 0,000 \\
\hline 3 & Practice & $\mathrm{T}$ & 2,43 & 0,87 & 2,72 & 0,74 & 2,18 & 0,028 \\
\hline 4 & Afraid & E & 1,85 & 0,80 & 3,08 & 0,69 & 7,17 & 0,000 \\
\hline 5 & Activated & B & 2,27 & 0,90 & 2,93 & 0,85 & 3,92 & 0,000 \\
\hline 6 & Breath & B & 2,20 & 1,02 & 2,84 & 0,92 & 3,49 & 0,000 \\
\hline 7 & Third & $\mathrm{T}$ & 1,63 & 0,88 & 3,49 & 0,64 & 8,48 & 0,000 \\
\hline 8 & Finger crossed & $\mathrm{T}$ & 1,88 & 0,98 & 3,39 & 0,75 & 7,28 & 0,000 \\
\hline 9 & Clutching & $\mathrm{T}$ & 2,50 & 0,72 & 2,54 & 0,77 & 0,39 & 0,696 \\
\hline 10 & Tough & B & 2,70 & 0,87 & 2,89 & 0,76 & 1,13 & 0,254 \\
\hline 11 & Tense & $E$ & 2,02 & 0,85 & 2,88 & 0,73 & 5,33 & 0,000 \\
\hline 12 & Opponents & $\mathrm{T}$ & 1,90 & 0,66 & 2,89 & 0,78 & 6,32 & 0,000 \\
\hline 13 & Relax & B & 2,57 & 0,79 & 2,49 & 0,70 & $-0,79$ & 0,423 \\
\hline 14 & Anger & B & 2,68 & 0,93 & 2,64 & 0,90 & $-0,14$ & 0,886 \\
\hline 15 & Stuck & E & 2,17 & 0,76 & 3,00 & 0,59 & 5,88 & 0,000 \\
\hline 16 & Pressure & $\mathrm{E}$ & 2,05 & 0,81 & 2,86 & 0,76 & 5,14 & 0,000 \\
\hline 17 & Calm & B & 2,30 & 0,79 & 2,82 & 0,87 & 3,28 & 0,001 \\
\hline 18 & Competition & B & 2,38 & 0,94 & 2,66 & 0,84 & 1,77 & 0,075 \\
\hline 19 & Thought & $\mathrm{T}$ & 1,85 & 0,94 & 2,55 & 0,89 & 4,05 & 0,000 \\
\hline 20 & Indecision & E & 2,83 & 0,89 & 2,62 & 0,78 & $-1,22$ & 0,220 \\
\hline
\end{tabular}

As shown in Table 2, the two clusters differ in 13 items, 6 of them related to the area of thoughts (items 2, 3, 7, 8, 12, 19), 4 to the emotions (items $4,11,15,16$ ) and 3 to the behaviors (items $5,6,17$ ).

\section{DISCUSSION}

This study shows how the awareness of one's own emotional experiences, the ability to recognize them in the court, to accept and manage them to obtain an effective performance seems to be more influenced by the expertise and the tennis skills rather than the players' age and gender. Moreover, these differences are in the area of thought, most likely because they make the difference in the emotional management between expert and less expert players. For the latter group small differences have been found in the behaviors to manage these difficulties, especially to release one's tension between the points rather than controlling anger after an unforced error.

The second cluster, that is the one composed of nonprofessional tennis players, reported more negative emotions such as tension, fear, pressure, and getting stuck. And most likely, for this reason, they perform different by behaviors to release tension and stay calm, such as breathing and activation.

These observations, according with the Labordeand colleagues review (2015) on the Emotional Intelligence in sport, could suggest that the ability to recognize and effectively manage emotions in the field may be associated with physiological stress responses and successful psychological skill usage, like the functional thougth.
For these reasons, since these skills are trainable, starting paths of literacy, recognition, awareness and then training will be necessary, will provide an increase in mental and emotional skills (not only tactics and technique), allowing the young players an optimal growth not only in tennis, but also as human beings.

\section{CONCLUSION}

In conclusion, the SPET tool represents a first step in the direction of increasing players' awareness and could be used by the coaches to compare their perception of the athletes with the one of their athletes, discussing about what happens on the court. Further studies should confirm the validity of the scale, as well as exceeding the limits of those groups wich are not homogeneous by gender and level.

However, SPET can also help sport psychologists to choose the best emotional training for each specific player, helping him/her to work on the emotional dimension that is most lacking during the match (awarness of emotions, thoughts or behaviors). The correct understanding of the assumptions that are in the minds of our children and athletes is an indispensable premise for an effective intervention and could help us create court-exercises allowing the athlete to experiment and manage their emotions.

\section{CONFLICT OF INTERESTS AND FUNDING}

The authors declare that they do not have any conflict of interest and that they did not receive any funding to conduct the research. 


\section{REFERENCES}

Costa, S., Livi, S. \& Polani, D. (2015). Una scala per la misura delle convinzioni di efficacia personale nel tennis. II Giornale Italiano Psicologia dello Sport, num. 24, 3-8, Calzetti Mariucci Editori.

Daino, A., \& Uberti, E. (2014). Le emozioni nel tennis: non sono interruttori ON/ OFF. Supertennis, 5, march.
Laborde S., Dosseville F., \& Allen M.S. (2015). Emotional Intelligence in sport and exercise: a systematic review. Scandinavian Journal of Medicine \& Science in Sports.

Merkel, D. L. (2013). Youth sport: positive and negative impact on young athletes. Open Access J Sports Med. 31;4:151-60.

Robazza C. (2006). Emotion in Sport: An IZOF Perspective. Literature Reviews in Sport Psychology, pp.127-158

Robazza, C. \& Ruiz, M. C. (2018). Emotional Self-Regulation in Sport and Performance. Oxford Research Encyclopedia of Psychology.

Copyright (c) 2021 Antonio Daino, Vanessa Costa, Riccardo Martoni \& Sergio Costa

\section{c) (i)}

This text is under a Creative Commons BY 4.0 license

You are free to Share - copy and redistribute the material in any medium or format - and Adapt the content - remix, transform, and build upon the material for any purpose, even commercially under the following terms:

Attribution: You must give appropriate credit, provide a link to the license, and indicate if changes were made. You may do so in any reasonable manner, but not in any way that suggests the licensor endorses you or your use.

CC BY 4.0 license terms summary. CC BY 4.0 license terms

RECOMMENDED ITF TENNIS ACADEMY CONTENT (CLICK BELOW)

ITF Academy 